\title{
GCU
}

Glasgow Caledonian

University

University for the Common Good

\section{A cost utility analysis of the clinical algorithm for nasogastric tube placement confirmation in adult hospital patients}

McFarland, Agi

Published in:

Journal of Advanced Nursing

DOI:

10.1111/jan. 13103

Publication date:

2017

Document Version

Author accepted manuscript

Link to publication in ResearchOnline

Citation for published version (Harvard):

McFarland, A 2017, 'A cost utility analysis of the clinical algorithm for nasogastric tube placement confirmation in adult hospital patients', Journal of Advanced Nursing, vol. 73, no. 1, pp. 201-216.

https://doi.org/10.1111/jan.13103

\section{General rights}

Copyright and moral rights for the publications made accessible in the public portal are retained by the authors and/or other copyright owners and it is a condition of accessing publications that users recognise and abide by the legal requirements associated with these rights.

Take down policy

If you believe that this document breaches copyright please view our takedown policy at https://edshare.gcu.ac.uk/id/eprint/5179 for details of how to contact us. 


\section{A cost utility analysis of the clinical algorithm for nasogastric tube placement confirmation in adult} hospital patients

\section{Abstract}

Aim: To evaluate the effectiveness of $\mathrm{pH}$ paper testing of aspirate and chest $\mathrm{x}$-ray for determining nasogastric tube placement in terms of cost and patient outcome.

Background: Nasogastric tubes are frequently used in clinical practice, however during insertion the practitioner is blinded as to the precise final location of the passed tube. Despite robust checking procedures, recognised patient morbidity and mortality associated with this procedure have resulted in recent national safety alerts prompting the revision of all clinical guidelines in relation to nasogastric tube care.

Design: Cost utility analysis using economic modelling.

Methods: A decision tree was built and populated with effectiveness data gathered from a systematic search of the extant literature base. Specificity, pooled sensitivity and event probabilities were calculated using statistical software. Patient outcome was measured in terms of quality of life. Health state utilities were gathered from a sample $(n=23)$ of adult surgical patients using a recognised instrument. Cost data was gathered using published sources. The study adopted a third party payer perspective in a Scottish context.

Results: The results confirm that the current UK algorithm advocated by the National Patient Safety Agency appears to offer the most cost effective approach to NGT confirmation in terms of cost and patient outcome. Sensitivity analyses indicate that these findings may be significantly altered by tube aspiration success and the rates of chest $\mathrm{x}$-ray interpretation errors.

Conclusion: The results confirm current UK recommendations and have wider policy implications for those areas whereby chest $\mathrm{x}$-ray is recommended as the first and only acceptable confirmation approach.

\section{Keywords}

Nursing

Nasogastric tubes

Cost utility analysis

Economic modelling 


\section{Why is this research or review needed?}

- Nasogastric tubes are frequently used in clinical practice but despite the availability of robust checking procedures, the procedure is still recognised as a cause of avoidable mortality and morbidity.

- Patient safety alerts have called for the review of all clinical guidelines in relation to nasogastric tube care.

- There is international disparity in the cost and effectiveness trade-off between the two most commonly used methods of nasogastric tube confirmation ( $\mathrm{pH}$ testing and $\mathrm{x}$-ray).

\section{What are the key findings?}

- Even if no complications occur, nasogastric tube insertion still impacts the patient's perceived health state.

- Compared to no checking procedure, chest $x$-ray is a more effective but more expensive approach than $\mathrm{pH}$ testing of aspirate for nasogastric tube placement confirmation.

- Using chest $x$-ray as the first line checking procedure for nasogastric tube placement confirmation without testing $\mathrm{pH}$ of aspirate significantly increases costs.

How should the findings be used to influence policy/practice/research/education?

- Current UK recommendations for nasogastric tube placement confirmation appear to be the most cost effective in terms of cost and patient outcome.

- Wider policy implications are evident for those areas whereby chest $\mathrm{x}$-ray is recommended as the first and only acceptable approach to nasogastric tube placement confirmation. 
Main file

\section{Main Text}

\section{INTRODUCTION}

Nasogastric tubes (NGT) are widely used within healthcare but carry with them a recognised morbidity and mortality risk. Although individual risk is low, given the extent of NGT usage an unacceptable amount of patient harm is resultant from these tubes on an annual basis. This finding is especially pertinent given that with correct placement confirmation, the entirety of this burden on patient harm may be eliminated (Krenitsky 2011). Several placement confirmation methods are available but of these only $\mathrm{pH}$ testing and chest $\mathrm{x}$-rays are advocated in UK clinical guidelines (National Patient Safety Agency (NPSA) 2011a). pH testing may be performed relatively cheaply at the bedside but at a lower accuracy than the more expensive chest $\mathrm{x}$-ray method (Ellet 2004). There is currently international disparity in the cost and effectiveness trade-off between these two tests, however no formal economic evaluation exists in the evidence base. The current study therefore attempts to address this knowledge gap.

\section{Background}

The insertion of a NGT is the passage of a tube, appropriate for its intended purpose, via the nostril into the stomach (National Institute for Clinical Excellence 2006). NGTs are used within clinical practice for a wide variety of reasons and thus NGT placement is an extremely common clinical intervention, with an estimated 170,000 feeding tubes being used annually in the United Kingdom alone (Eveleigh 2011). Although the majority of these tubes are inserted and used without incident, there is a recognised risk that the tube can be misplaced into the lungs, or move out of the stomach (Burns et al. 2001).

Confirmation of NGT placement is required immediately following insertion and subsequently prior to each use (for example, administration of enteral feed or medication). Additionally, the tube should be checked following episodes of vomiting, retching or coughing spasms, after oropharyngeal suction has been required or where there is a suggestion of tube displacement. Any new or unexplained respiratory symptoms or a drop in oxygen saturation readings is a further indication for seeking repeated confirmation of NGT placement (Durai et al. 2009).

$\mathrm{pH}$ testing of gastric aspirate obtained via the NGT is recommended as a first line test method for establishing correct position. A pH reading of between $1-5.5$ is considered a reliable method for excluding placement in the pulmonary tree; however is not a definitive confirmation of gastric placement. When aspirate is not able to obtained, or first line $\mathrm{pH}$ testing is inconclusive, national guidelines recommend placement confirmation with a chest x-ray (NPSA 2011b). These tests may only be foregone in patients where the placement of the NGT is completed under direct visualisation of a surgeon or anaesthetist (for example, patients undergoing gastric surgery or endoscopy procedures) (NPSA 2011a).

Although the majority of these tubes are inserted and used without incident, there is a recognised risk that the tube can be misplaced into the lungs, or move out of the stomach. Published reports of incidents have included oesophageal, peritoneal and intestinal placement, and NGTs placed within the brain (Burns et al. 2001). Additionally, severe pulmonary complications, indeed mortality, have been reported as a direct result of NGT placement within the respiratory tract (Miller 2011). 


\section{CUA OF NG TUBE CHECKING}

Main file

Between September 2005 and March 2010, 21 deaths and 79 cases of harm relating to feeding through misplaced NGTs were reported (NPSA 2011a). Due to these serious consequences, NGT misplacement was included as one of the eight 'Never Events' identified by the NSPA (2010a).

Despite this, the second highest reported Never Event in the period between $2009-2010$ was NGT misplacement, with 41 reports of significant patient safety incidents (NPSA 2010b). Additionally, a number of these incidents occurred despite the recommended first and second line tests being undertaken, with the NPSA directly attributing 45 incidents between 2005 and 2011 to cases of misinterpretation (NPSA 2011b).

With recent national safety alerts prompting the revision of all clinical guidelines in relation to NGT care, a formal evaluation which assesses the outcomes of patients in relation to the two currently recommended methods is timely and indicated. Clinical guidelines from the United States outline that blindly placed NGT placement should always be verified radiologically (Metheny 2009). There is, therefore, international disparity in the decision making trade-off between the more efficacious but costly chest $\mathrm{x}$-ray alternative against the cheaper but potentially less specific $\mathrm{pH}$ testing of aspirate. The existence of this disparity demonstrates that robust evaluations of the current methods for NGT placement confirmation in terms of both patient outcomes and cost are not yet available. An economic evaluation of the currently recommended confirmation algorithm will inform future guideline development and has clear policy implications for patient safety on both a national and international platform.

\section{THE STUDY}

\section{$\operatorname{Aim} / \mathrm{s}$}

The aim of this research was to evaluate the effectiveness of $\mathrm{pH}$ paper testing of aspirate and chest $x$-ray as outlined in the currently recommended NPSA algorithm (NPSA 2011c) for determining NGT placement in terms of cost and patient outcome for adult patients.

\section{Design}

This study was a cost utility analysis comparing the costs and consequences of using chest x-ray versus $\mathrm{pH}$ testing of aspirate as first line procedures for checking NGT placement. Consequences were measured in terms of quality of life using quality adjusted life years (QALYs).

The study adopted a third party payer perspective (NHS) based in Scotland. The time horizon was set at 6 weeks, in line with the NICE (2006) definition of short term NGT placement and incorporating the average length of inpatient hospital stay (4.8 days) in the study setting (ISD Scotland 2012a). Given the short time horizon, a 0\% discount rate was applied (Husereau et al 2013).

\section{Sample/Participants}

In order to increase the homogeneity of the patient group and increase the validity of the comparison, the patient population inclusion criteria were:

- adult patients; defined through admission to an adult care area

- short term NGT placement; defined as up to 6 weeks (NICE 2006)

- hospital setting 
CUA OF NG TUBE CHECKING

Main file

- receiving general care; defined as no artificial airway insitu

\section{Data collection}

Measurement of effectiveness

A systematic search of literature was undertaken using Cochrane Collaboration methodology (Higgins \& Green 2011). The criteria for considering studies are summarised in Table 1, and a flow diagram of the search results is presented in Figure 1.

A total of three studies were included in the synthesis for chest x-ray effectiveness (Gharemani and Gould 1986, Sorokin and Gootlieb 2006, de Aguilar-Nascimento and Kudsk 2007). Details of the complications were assessed individually and grouped according to the criteria where Low Harm was indicated by no additional treatment required and no delay in discharge, Moderate Harm requiring some additional treatment within the same care area and a slight delay in discharge and Severe Harm as requiring additional extensive treatment with care in a higher dependent area (such as HDU or ITU) and a significant delay in discharge home. A summary of the data is provided in Table 2.

No single studies were available which evaluated the performance of $\mathrm{pH}$ testing in relation to specific complication rates and patient outcomes, therefore the effectiveness data were calculated using a two stage approach. Initially to calculate effectiveness, a total of three studies were identified (Metheny et al 1999, Metheny, Smith and Stuart 2000, Kearns and Donna 2001)and data were extracted and used to construct $2 \times 2$ tables of true positive, false positive, true negative and false negative cases for each. All data were classified as binary (either gastric placement, or not) therefore no threshold for test positivity was required (Deeks et al 2010). Sensitivity, specificity and a $95 \% \mathrm{Cl}$ for each study were then calculated using RevMan 5.2 software (The Nordic Cochrane Centre, The Cochrane Collaboration 2012). Finally, these data were combined in meta-analysis using Meta-DiSc 1.4 software (Zamora et al 2006) to calculate the pooled sensitivity of pH testing across the three studies (sensitivity $0.823, \mathrm{Cl} 0.803-0.843$ ).

A further three studies (Metheny et al 1989, Welch et al 1994, Neumann, Meyer and Dutton 1995) were added to two from the meta-analysis to calculate the probability of obtaining aspirate from the NGT (Table 3). The study by Metheny, Smith and Stewart (2000) was excluded from this calculation as data were reported on aspirate $\mathrm{pH}$ ability to detect correct NGT placement, not the ability to obtain aspirate for testing. All possible outcomes were assumed equally likely and therefore probability was calculated by dividing the number of instances of aspiration success by the total number of attempts. Finally, probability weights for complication incidence were calculated from published NRLS patient safety incident report data (NPSA 2008) with the levels of complication calculated from narratives of these incidents provided in Hannah et al's (2010) NHS report into improving NGT safety. Overall probability of complications was calculated as per aspiration success. The number of complications was used as the denominator when calculating probability weights for each level of harm.

\section{Measurement and valuation of preference based outcomes}

Utility values for health states were sought in which following NGT placement confirmation no complications, mild, moderate and severe complications were encountered. As none were available in the existing literature, these were gathered directly from patients. A sample of 31 patients 
Main file

admitted to an acute surgical unit were provided with four vignettes of the health states under consideration and asked to value each one using the EQ-5D instrument (The EuroQol Group 1990). The vignettes described four scenarios involving NGT insertion and checking, ranging from a simple insertion and check with no complications to an NGT insertion that resulted in significant, severe complications which required intervention and an extended hospital stay. The vignettes were based on actual NGT placement related adverse events reported by Hannah et al (2010) and were supported by a patient information sheet including details of the clinical indication of a NGT and the checking procedures. Participants were asked to imagine they were the patient described in the scenario and rate the impact of the hypothetical events on their health and wellbeing using the scoring tools in the EQ-5D.

Seven patients declined participation; one agreed but did not complete the documentation resulting in a final sample of 23 . The EQ-5D was self-administered and completed anonymously.

The ratings for each health state were converted using the EQ-5D-5L Value Sets Crosswalk Index Value Calculator and also calculated using the visual analogue scale (VAS) scores. The recommendations of Dolan (2000) were used to aggregate the valuations for each health state, with the skewed distribution (for all health state valuations expect Moderate Complications) guiding the choice of median (with $25^{\text {th }}$ and $75^{\text {th }}$ percentiles) over mean for QALY calculations.

\section{Estimating resources and costs}

Cost data utilised current NHS prices in relation to consumables and investigation costs. Staff costs in terms of time were calculated using the midpoint of the NHS pay scale for all relevant staff members required. Oncosts were considered in accordance with the perspective of the study. Costs for repeated chest $\mathrm{x}$-ray placement confirmation when first attempt failed were calculated in terms of marginal costs. Given 6 week NHS usage of NGT of 31269 tubes (NPSA 2008) and a failure to confirm rate of $6 \%$ (Rollins et al 2012) a maximum of 3 repeats (in addition to the original $x$-ray) were calculated and costed accordingly. Summary estimates of costs are outlined in Table 4.

\section{Ethical considerations}

Ethical approval was sought from the local NHS ethics committee for the valuation of preference based outcomes but was deemed not necessary due to the nature of the information sought. The project was considered a service evaluation.

\section{Data analysis}

All data were analysed using a decision tree model built using TreeAge Pro Healthcare software (TreeAge Software Inc 2013). The model structure and all study parameters entered can be seen in Figure 2.

\section{Validity and reliability/ Rigour}

The model required a number of assumptions. As the time horizon was set at 0.125 years, no discounting was applied. The baseline patient characteristics were adult surgical patients with no artificial airway insitu and not nursed in a low to medium dependency area. The model assumes one NGT per patient over the time horizon of the study. Efficacy of each method (pH testing and chest $\mathrm{x}$ - 


\section{CUA OF NG TUBE CHECKING}

Main file

ray) was expressed in terms of probability of complication and level of complication, with the ability to confirm NGT position per $\mathrm{x}$-ray set at $94 \%$ (failure rate of $6 \%$ ) and ability to obtain aspirate for $\mathrm{pH}$ testing set at $87 \%$ (failure rate of $13 \%$ ). If the NGT position was not confirmed within $2 \mathrm{x}$-rays, the model assumes that the checking procedure would be abandoned.

In terms of cost inputs, radiology staff costs were incorporated into the costs of the x-ray, with interpretation costs separate. Low complications assumed no additional treatment was required, moderate complications required additional ward bed days, chest drain insertion and additional care and severe complications required intensive care. Only the costs of the confirmation method were used for the Death health state outcome.

In terms of utility inputs, the model assumed that these would be the same for each health state outcome, regardless of checking procedure. Where the checking procedure is abandoned (i.e. when no method can confirm placement), no utility is gained.

Base case assumptions and parameter uncertainties were explored using one way deterministic sensitivity analysis.

\section{RESULTS}

\section{Utility of NGT placement and subsequent complications}

The EQ-5D instrument was completed anonymously; therefore no sample characteristics are available to report. Given the nature of the care area (an adult surgical unit), it can be assumed that all participants were over 16 years of age.

Despite experiencing no complications, the insertion of an NGT still resulted in a slight dip in health, as rated by the 23 participants. As expected, the utility values decrease as the severity of complications with NGT placement increase. The mean and median values remain similar using the VAS utility values, contrasted with those obtained from the index ratings. Overall, utility ratings for all health states were higher using the VAS part of the EQ-5D instrument with the most noticeable difference in Severe Complications health state. See Table 4 for a summary.

\section{Cost utility}

The base case is compared to no checking procedure and thus zero utility attributed to a nonfunctioning NGT. Each checking procedure was considered in turn as the base case (pH testing and chest $\mathrm{x}$-ray).Compared to no checking procedure, chest $\mathrm{x}$-ray delivers a higher QALY gain than $\mathrm{pH}$ testing when compared no checking procedure (0.12 QALYs vs. 0.11 QALYs) but also at higher cost ( $x$-ray costs $f 1322.00$ per QALY gained, $\mathrm{pH}$ testing $£ 392.73$ per QALY gained). If the base case is altered to $\mathrm{pH}$ testing, the cost effectiveness in terms incremental cost effectiveness ratio (ICER) for chest $x$-ray rises significantly. Compared to no checking procedure, the cost per QALY of checking NGT position by $x$-ray alone without attempting aspiration for $\mathrm{pH}$ testing first is $\mathrm{f} 11544$.

\section{Sensitivity analysis}

Aspiration success has considerable impact on the ICER of $\mathrm{pH}$ testing, with lower success rates resulting in a $22 \%$ increase from the base case. $\mathrm{pH}$ confirmation success rate had only marginal impact, which appears logical given the narrow confidence interval range. Upper and lower bound 


\section{CUA OF NG TUBE CHECKING}

Main file

chest $x$-ray complication rates also resulted in significant alterations to the base case ICER. Again, this appears logical given that chest $x$-ray is the "back up" confirmation method when aspiration or $\mathrm{pH}$ testing confirmation fails. Using VAS utility values results in a $10 \%$ increase in ICER, a result driven by the higher health state valuations using this instrument of the EQ-5D tool. When the cost of Death health state is considered to equal that of Severe Complications, an increase of $29 \%$ is noted from the $\mathrm{pH}$ base case ICER.

Upper and lower bound chest $\mathrm{x}$-ray complication rates also greatly impact the chest $\mathrm{x}$-ray ICER. Lower complication rates result in an ICER decrease of 19.5\%. Again, the higher VAS health state valuations impacted on the ICER (around a 10\% increase) and the impact of the increased cost of Death health state resulted in a $33 \%$ increase in ICER, slightly more than the increase noted for $\mathrm{pH}$ testing in the same analysis. A summary of the base case cost utility results and sensitivity analyses can be found in Table 5 .

\section{DISCUSSION}

NGT placement is an extremely common clinical intervention with the majority of tubes passed without complication. However there is a recognised risk that during the procedure, because the practitioner is blinded to the final placement, the NGT may be misplaced into the lungs. Placement confirmation methods are therefore required and currently, $\mathrm{pH}$ testing of aspirate and chest $\mathrm{x}$-ray is recommended in UK national guidelines (NPSA 2011c) although international disparity exists on best practice recommendations (Metheny 2009). Additionally, no previous economic evaluation has been completed which compares the two currently recommended confirmation methods.

Clinical outcome was measured through QALY gains, adjusted to the 0.125 year timeline of the study. In terms of effectiveness, both $\mathrm{pH}$ testing and chest $\mathrm{x}$-ray produce QALY gains when compared to no checking procedure. Chest $x$-ray produces a slightly higher QALY (0.01) than pH testing. In terms of cost, compared to a base case of no confirmation procedure, the incremental cost of $\mathrm{pH}$ testing is $£ 43.20$ which is significantly lower than the $£ 158.64$ of chest $\mathrm{x}$-ray. This results in an ICER for $\mathrm{pH}$ testing of $£ 392.73$ per QALY, over a third lower than chest $\mathrm{x}$-ray (ICER $f 1322$ per QALY). When compared to a base case of $\mathrm{pH}$ testing, foregoing any attempt to aspirate the NGT in the first instance, the costs of chest $x$-ray as first line confirmation results in a significantly higher ICER of $£ 11544$ per QALY gained. This appears logical given that chest $x$-ray confirmation offers only a 0.01 QALY gain over $\mathrm{pH}$ testing as a first line attempt. As no previous work has evaluated the cost effectiveness of the NGT checking procedure, a comparison to other published work as recommended by Phillips et al (2004) is not possible.

The current UK algorithm advocated by the NPSA (2011c) therefore appears to offer the most cost effective approach to NGT confirmation in terms of QALYs gained. However, the results of the sensitivity analysis indicate that these findings may be significantly altered by NGT aspiration success and the rates of chest $\mathrm{x}$-ray interpretation errors. The ability of obtaining aspirate from a NGT for $\mathrm{pH}$ testing may be influenced by a number of factors. Smaller bore feeding tubes are more liable to collapse when negative pressure is applied (Crocker et al 1981), with Silk et al (1987) also finding that changing the material of the tube itself (from polyvinyl chloride to polyurethane) leads to significant $(p<0.001)$ increases in aspiration attempt success. It should be noted that the probability of obtaining aspirate for the current study was calculated at 0.87 from five studies identified as part 
Main file

of the systematic literature search, with two studies from Metheny et al $(1989,1999)$. Norma Metheny is extensively published in the field of NGT care and is considered an expert in the field. Indeed, she has published specific guidelines on how to maximise aspiration success of NGTs (Metheny et al 1993). The two studies from Metheny et al $(1989,1999)$ contributed to over half of the data (57\%) for the estimation of aspiration success for this current work and therefore may have increased the estimate to above what may be achieved by non-experts in the field. Sensitivity analysis was utilised using a range of aspiration success rates to explore this impact on the study ICER estimate. Similarly, in a systematic review by Sparks et al. (2011) clinician experience in x-ray interpretation was found to impact on the rate of complications encountered. Estimation of complication rates for chest $\mathrm{x}$-ray in the current study was generated using observational data and therefore should better reflect the heterogeneity of clinicians' interpretation abilities in actual clinical practice (Black 1999). Sensitivity analyses facilitated a further exploration of the impact of this potential variable on the study ICER estimates. However, it should be noted that strategies to improve chest x-ray interpretation for NGT placement confirmation (and thus lower complication rates) such as the training tool described by Eveleigh et al (2011) also carry a cost which may offset any savings gained. If such strategies are utilised then the additional cost of training needs to be considered in any future economic evaluation, particularly if the third party payer perspective is maintained.

Alterations in the base case resulted in significant increases in the cost per QALY gained. This finding has particular relevance to international clinical policy comparisons. The model for the current work mirrors the current UK NGT placement confirmation algorithm advocated by the NPSA (2011c), whereby first line checking should begin with attempt at aspiration for $\mathrm{pH}$ testing before proceeding to chest x-ray. However, new clinical guidelines endorsed by professional bodies in the USA, Canada and Europe state that "every patient should undergo radiography to confirm proper position of an NG or OG tube before feeding is initiated" (Itkin et al 2011, p746). The study model demonstrates that foregoing $\mathrm{pH}$ testing as a first line method of NGT placement confirmation results in an increase in cost per QALY gained of $f 10222$. Even accounting for the potential lack of precision of $p H$ testing and subsequent possible complications, it appears that utilising this cheap (incremental cost of f4.40) bedside test as a first line method offers a more cost effective approach to NGT placement confirmation in terms of cost per QALY gained. This is particularly significant when considered in light of the frequency of the NGT placement confirmation procedure, estimated by Krenitsky (2011) to be 1.2 million annually in the USA alone.

The current study setting was the Scottish NHS and a third party payer perspective was adopted. Since the passing of the Scotland Act (Great Britain Parliament 1998) the powers to run the NHS in Scotland have been devolved to the Scottish Government. As a result, NHS Scotland displays some systemic differences to that of NHS England and Wales. One of these differences is the Never Event framework (Department of Health 2011). This list of 25 preventable events carries a financial penalty for the provider if they occur, with a $£ 10,000$ payment levied on top of the recovery of costs of care and procedures to date should a death occur (NPSA 2010a). To enable extrapolation of the study results to the wider UK perspective, the cost of a never event due to misplaced NGT ( $£ 10,000$ plus costs of Severe Complications health state) was added to the model. The resultant incremental costs are an increase of $£ 19.74$ for $\mathrm{pH}$ testing and $£ 82.74$ for chest $\mathrm{x}$-ray compared to the Scottish NHS base case for the same QALY gains. Consequently the ICERs are also increased by $46 \%$ and $52 \%$ for $\mathrm{pH}$ testing and chest $\mathrm{x}$-ray respectively. $\mathrm{pH}$ testing therefore still remains the most cost effective 
Main file

option in terms of incremental cost and QALYs gained when compared to no checking, therefore the national NPSA algorithm (2011c) is correctly used throughout the UK. However, it should be noted that the cost of obtaining QALY gains through NGT placement confirmation in the NHS England and Wales context is considerably higher than in NHS Scotland. This result is driven purely by the policy differences between the two bodies.

\section{Limitations}

The generalisability of the study results are limited to the base case patient demographic and setting (i.e. adult surgical patients with no airway insitu receiving general ward based care). A number of factors are known to increase the incidence of complications with NGT placement such as age, with paediatric populations at higher risk than adults (Ellet et al 1998). Additionally, bronchial placement of NGTs is more prevalent amongst patients with reduced conscious levels or those receiving mechanical ventilation (Stroud et al 2003). As such, the findings from this study would represent an underestimate if applied to these high risk groups. However, as heterogeneity is known to impact on both costs and effectiveness (Coyle et al 2003), it would not have been appropriate to include both high and normal risk groups here for the comparison under study. The economic model structure accurately mirrors the current NPSA algorithm (NPSA 2011c) and therefore could be easily used and updated with data for various subgroups to gain ICER estimates for the NGT placement confirmation procedure across a variety of risk profiles.

There was an acknowledged lack of data pertaining to the specific study setting (Scotland) and as a result data from other areas of the UK were used. Although this may influence the study results, where possible NHS based information was utilised to minimise the impact of this potential bias. Additionally, a reliance on published data for a variety of model inputs (for example, complication rates and outcomes) may impact the study results through publication bias (Easterbrook et al 1991). An attempt to minimise this impact was undertaken through a systematic approach to literature searching and extending the search to include grey literature. Additionally, the UK NHS perspective may limit the transferability of the study findings to international settings. However, given the results of the sensitivity analysis it would be anticipated that similar results would be generated in other health care systems whereby $\mathrm{pH}$ testing was associated with lower costs when compared to the chest x-ray checking procedure.

In line with recommendations of Brazier et al (2005) and Ubel et al (2003) that those patients who are experiencing the health state are best place to value them, the study results would have been enhanced if valuations were gathered from patients who had actually underwent NGT placement confirmation and subsequent complications (or not). The EQ-5D questionnaire was delivered as a self-completion questionnaire in line with the intended design of the instrument (Rabin et al 2011). However, this also prevented the patients from clarifying any misunderstanding they may have had in completing the health state valuations. The presence of misunderstanding or unfamiliarity with the EQ-5D instrument is suspected due to a number of anomalous ratings (for example, Moderate Complications Health State being rated considerably higher at 0.877 than No Complications Health State at 0.143 by one participant)and the extremely low overall combined utility score of Severe Complications Health State at 0.036 . In practical terms, this means that participants valued Severe Complications as being very near 0 , the score representing death on the EQ-5D instrument.

Additionally, gaining access to actual patient data pertaining to complication rates and outcomes in terms of additional care required would have facilitated a more accurate representation than the 


\section{CUA OF NG TUBE CHECKING}

Main file

current literature based approach. Currently, the study assumes a set profile of care for each level of complication, with a specific focus on bronchopulmonary complications as these are the most common (Sparks et al 2011). However, single case studies are available which report on a wider variety of complications (for example, Pandey et al 2004). Although these are extremely rare their inclusion may impact on the current study estimates. By accessing actual patient level data, this limitation to the current study may be addressed.

A final consideration is the sample size of 23 for health state valuations. Although debate exists in the literature regarding optimal sample size calculations for cost effectiveness analyses (Briggs \& Gray 1998, Laska et al 1999), a larger sample size for this current work would have potentially provided a more accurate estimate of health state valuations with smaller SEs than the current sample.

\section{CONCLUSION}

The aim of the current study was to evaluate the effectiveness of $\mathrm{pH}$ paper testing of aspirate and chest x-ray as outlined in the currently recommended NPSA algorithm (NPSA 2011c) for determining NGT placement in terms of cost and patient outcome for adult patients. Using economic modelling, an ICER was calculated in terms of costs of checking and subsequent complications and QALY gains. The study adopted a third party payer perspective (NHS) in a Scottish setting. The time horizon for the study was 0.125 years in line with the recommendations for duration of short term NGT use and incorporating average length of stay for the population under consideration (hospitalised adult patients in Scotland). Patient outcome was measured in terms of QALYs gained. QALY values were obtained using a generic validated questionnaire and calculated for the 0.125 year time horizon. A systematic search of the literature was conducted to source effectiveness data and probability rates for complications and consequences. Sensitivity analysis was conducted to test the final model assumptions and uncertainties around the model inputs. Although the success of aspiration attempts and chest $x$-ray interpretation accuracy were found to significantly alter the ICER estimates, the current recommendation of $\mathrm{pH}$ testing of aspirate as a first line approach for the confirmation of NGT placement remains the most cost effective method in terms of cost and patient outcome (measured through QALY gains). The results confirm current UK recommendations from the NPSA (2011c) and may have wider policy implications for those areas whereby chest $\mathrm{x}$-ray is recommended as the first and only acceptable confirmation approach. 
CUA OF NG TUBE CHECKING

Main file

\section{$\underline{\text { References }}$}

Black, N (1999) What observational studies can offer decision makers. Hormone Research 51 , 44-9.

Brazier, J, Acehurst, R, Brennan, A, Dolan, P, Claxton, K, McCabe, C, Sculpher, M, Tsuchyia, A (2005) Should patients have a greater role in valuing health states? Applied Health Economics and Health Policy 4, 201-8.

Briggs, AH, Gray, AM (1998) Power and sample size calculations for stochastic cost-effectiveness analysis. Medical Decision Making 18, S81-S92.

Burns, SM, Carpenter, R, Truwit, JD (2001) Report on the development of a procedure to prevent placement of feeding tubes into the lungs using end tidal $\mathrm{CO} 2$ measurements. Critical Care Medicine 29, $936-9$.

Coyle, D, Buxton, MJ, O'Brien, BJ (2003) Stratified cost-effectiveness analysis: a framework for establishing efficient limited use criteria. Health Economics 12, 421-7.

Crocker, KS, Krey, SH, Steffee, WP (1981) Performance Evaluation of a New Nasogastric Feeding Tube. Journal of Parenteral and Enteral Nutrition 5, 80-2.

de Aguilar-Nascimento, JE, Kudsk, KA (2007) Clinical Costs of Feeding Tube Placement. Journal of Parenteral and Enteral Nutrition 31, 269-72.

Deeks, JJ, Bossuyt, PM, Gatsonis, C (eds.) (2010) Cochrane Handbook for Systematic Reviews of Diagnostic Test Accuracy Version 1.0 [Internet]. Available at: http://srdta.org/. (Accessed 22.01.15)

Department of Health (2011) The "never events" list 2011/12 Policy framework for use in the NHS. [Internet] Available at:

https://www.gov.uk/government/uploads/system/uploads/attachment data/file/216724/dh 12458 0.pdf (Accessed 02.02.15).

Department of Health (2012). NHS Reference Costs 2011-12. [Internet] Available at: https://www.gov.uk/government/publications/nhs-reference-costs-financial-year-2011-to-2012 (Accessed 14.01.16)

Dickson, J, Mann, S (2011) Pneumothorax complicating nasogastric tube insertion. Gastroenterology Today 21, 4, 84-6.

Dolan, P (2000) Chapter 32: The measurement of health-related quality of life for use in resource allocation decisions in health care. Handbook of Health Economics 1, 1723-60.

Durai, R, Venkatran, R, Ng, PCH (2009) Nasogastric tubes 1: insertion technique and confirming position. Nursing Times 105, $3-12$.

Easterbrook, PJ, Gopolan, R, Berlin, JA, Mathews, DR (1991) Publication bias in clinical research. The Lancet 337, 867-72.

Ellet, ML, Maahs, J, Forsee, S. (1998). Prevalence of feeding tube placement errors \& associated risk factors in children. The American Journal of Maternal/Child Nursing 23, 234-9.

Ellet, MLC (2004) What Is Known About Methods of Correctly Placing Gastric Tubes in Adults and 
Main file

Children. Gastroenterology Nursing 27, 253-9.

Eveleigh, M, Law, R, Pullybank, A, Bennett, J (2011) Nasogastric feeding tube placement: changing culture. Nursing Times 107, 14-6.

Ghahremani, GG, Gould, RJ (1986) Nasoenteric Feeding Tubes Radiographic Detection of Complications. Digestive Diseases and Sciences 31, 574-85.

Great Britain Parliament (1998) Scotland Act 1998 (Act of Parliament). London, HMSO.

Hannah, G, Phillips, L, Priest, O, Ni, Z (2010) Improving the safety of nasogastric feeding tube insertion. Developing guidelines for the safe verification of feeding tube position - a decision analysis approach. A Report for the NHS Patient Safety Research Portfolio. [Internet]. Available at: http://www.birmingham.ac.uk/Documents/college$\mathrm{mds} /$ haps/projects/cfhep/psrp/finalreports/PS048Improvingthesafetyofnasogastricfeedingtubeinser tionREVISEDHannaetal.pdf (Accessed 22.01.15).

Higgins, JPY, Green, S (eds.) (2011) Cochrane Handbook for Systematic Reviews of Interventions Version 5.1.0 [Internet]. Available at: www.cochrane-handbook.org (Accessed 22.01.15).

Husereau, D, Drummond, M, Petrou, S, Carswell, C, Moher, D, Greenberg, D, Augustovski, F, Briggs, AH, Mauskopf, J, Loder, E, CHEERS Good Reporting Practices Task Force (2013) Consolidated Health Economic Evaluation Reporting Standards (CHEERS)--explanation and elaboration: a report of the ISPOR Health Economic Evaluation Publication Guidelines Good Reporting Practices Task Force. Value in Health 16, 231-50.

ISD Scotland (2012) Number of inpatient episodes, length of stay and average length of stay by admission type. [Internet]. Available at: http://www.isdscotland.org/Health-Topics/HospitalCare/Inpatient-and-Day-Case-Activity/ (Accessed 21.01.15).

ISD Scotland (2012b) Summary of Scottish Health Service Costs Year ended March 2012. ISD Scotland, Edinburgh.

Itkin, M, DeLegge, MH, Fang, JC, McClave, SA, Kundu, S, d'Othee, BJ, Martinez-Salazar, GM, Sacks, D, Swan, TL, Towbin, RB, Walker, TG, Wojak, JC, Zuckerman, DA, Cardella, JF (2011) Multidisciplinary Practical Guidelines for Gastrointestinal Access for Enteral Nutrition and Decompression From the Society of Interventional Radiology and American Gastroenterological Association (AGA) Institute, With Endorsement by Canadian Interventional Radiological Association (CIRA) and Cardiovascular and Interventional Radiological Society of Europe (CIRSE). Gastroenterology 141, 742-65.

Kearns, PJ, Donna, C (2001) A Controlled Comparison of Traditional Feeding Tube Verification Methods to a Bedside Electromagnetic Technique. Journal of Parenteral and Enteral Nutrition 25, 210-5.

Laska, EM, Meisner, M, Siegel, C (1999) Power and Sample Size in Cost-Effectiveness Analysis. Medical Decision Making 19, 339-43.

Lo, JO, Wu, V, Reh, D, Nadig, S, Wax, MK (2008) Diagnosis and Management of a Misplaced Nasogastric Tube Into the Pulmonary Pleura. JAMA Otolaryngology - Head \& Neck Surgery 134 , 5 , 547-50. 
Main file

Metheny, N (2009) AACN Practice Alert. Verification of feeding tube placement (blindly inserted). [Internet]. Available from:

http://www.aacn.org/WD/Practice/Docs/PracticeAlerts/Verification of Feeding Tube Placement 0 5-2005.pdf (Accessed 21.01.15).

Metheny, NA, Reed, L, Worseck, M, Clark, J (1993) How to Aspirate Fluid from Small-Bore Feeding Tubes. American Journal of Nursing 93, 86-8.

Metheny, NA, Smith, L, Stewart, BJ. (2000). Development of a Reliable and Valid Bedside Test for Bilirubin and it's Utility for Improving Prediction of Feeding Tube Location. Nursing Research. 49, 6, 302-9.

Metheny, NA, Stewart, BJ, Smith, L, Yan, H, Diebald, M, Clouse, RE (1999) pH and Concentration of Bilirubin in Feeding Tube Aspirates as Predictors of Feeding Tube Placement. Nursing Research 48, 189-97.

Metheny, NA, Williams, P, Wiersema, L, Wehrle, MA, Eisenberg, P, McSweeney, M (1989)

Effectiveness of $\mathrm{pH}$ measurements in predicting feeding tube placement. Nursing Research 38, 2805.

Miller, SL (2011) Capnometry vs. pH testing in nasogastric tube placement. Gastrointestinal Nursing $9,30-3$.

National Institute for Clinical Excellence (2006) Nutrition Support for Adults Oral Nutrition Support, Enteral Tube Feeding and Parental Nutrition. National Collaborating Centre for Acute Care, London.

National Patient Safety Agency (2008) Quarterly Data Summary Issue 9: Learning from reporting nasogastric tube incidents [Internet] Available at:

http://www.nrls.npsa.nhs.uk/resources/collections/quarterly-datasummaries/?entryid45=59851\&p=2 (Accessed 22.01.15)

National Patient Safety Agency (2010a) Never Events Framework: Updated 2010/11. [Internet] Available at: http://www.nrls.npsa.nhs.uk/resources/?Entryld45=68518 (Accessed 03.03.15).

National Patient Safety Agency (2010b) Never Events Annual Report 2009/10. National Patient Safety Agency, London.

National Patient Safety Agency (2011a) Reducing the harm caused by misplaced nasogastric feeding tubes in adults, children and infants. National Patient Safety Agency, London.

National Patient Safety Agency (2011b) Patient Safety Alert NPSA/2011/PSA002: Reducing the harm caused by misplaced nasogastric feeding tubes in adults, children and infants. Supporting Information. National Patient Safety Agency, London.

National Patient Safety Agency (2011c). Nasogastric feeding tubes - decision tree adults. [Internet]. Available at: http://www.nrls.npsa.nhs.uk/resources/?Entryld45=129640 (Accessed 15.01.15).

Pandey, AK, Sharma, AK, Diyora, BD, Sayal, PP, Ingale, HA, Radhakrishnan, M (2004) Inadvertent insertion of nasogastric tube into the brain. Journal of the Association of Physicians of India 52, 3222. 


\section{CUA OF NG TUBE CHECKING}

Main file

Patrick, PG, Marulendra, S, Kirby, DF, DeLegge, MH (1995) Endoscopic nasogastric-jejunal feeding tube placement in critically ill patients. Gastrointestinal Endoscopy $45,1,72-6$.

Philips, Z, Ginnelly, L, Scuplher, M, Claxton, K, Golder, S, Riemsma, R, Woolacott, N, Glanville, J (2004) Review of guidelines for good practice in decision-analytical modelling in health technology assessment. Health Technology Assessment 8, 1-169.

Rabin, R, Oemar, M, Oppe, M, Janssen, B, Herdman, M (2011) EQ-5D-5L User Guide Version 1.0. EuroQol Group [Internet] Available at: www.euroqol.org (Accessed 22.02.15)

Rollins, H, Arnold-Jellis, J, Taylor, A (2012) How accurate are X-rays to check NG tube placement? Nursing Times 108, 14-6.

Silk, DBA, Rees, RG, Keohane, PP, Attrill, H (1987) Clinical Efficacy and Design Changes of "Fine Bore" Nasogastric Feeding Tubes: A Seven-Year Experience Involving 809 Intubations in 403 Patients. Journal of Parenteral and Enteral Nutrition 11, 378-83.

Sparks, DA, Chase, DM, Coughlin, LM, Perry, E (2011) Pulmonary Complications of 9931 Narrow-Bore Nasoenteric Tubes During Blind Placement: A Critical Review. Journal of Parenteral and Enteral Nutrition 35, 625-9.

Stroud, M, Duncan, H, Nightingale, J (2003) Guidelines for enteral feeding in adult hospital patients. Gut 52, vii1-vii12.

The EuroQol Group (1990) EuroQol - a new facility for the measurement of health-related quality of life. Health Policy 16, 199-207.

The Nordic Cochrane Centre, The Cochrane Collaboration (2012) Review Manager (RevMan) Version 5.2. Copenhagan, The Nordic Cochrane Centre, The Cochrane Collaboration.

Welch, SK, Hanlon, MD, Waits, M, Foulks, CJ (1994) Comparison of four bedside indicators used to predict duodenal feeding tube placement with radiography. Journal of Parenteral and Enteral Nutrition 18, 525-30.

Zamora, J, Abraira, V, Muriel, A, Khan, KS, Coomarasamy, A (2006) Meta-DiSc: a software for metaanalysis of test accuracy data. BMC Medical Research Methodology 6 , 1-12. 
Main file

Figure 1

Database searches:

1. Medline: 91

2. Embase: 79

3. CINAHL:

4. JBI EBP:

Grey literature:

1. Conference proceedings 0

2. Reference lists 12

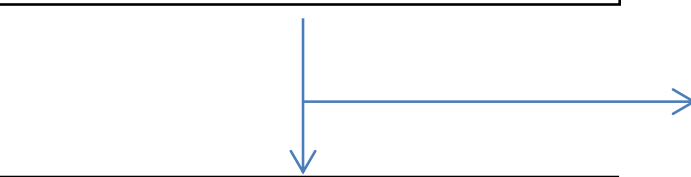

281 excluded based on abstract and title review

27 potentially relevant studies

Figure 1: Flow diagram of search results

$\begin{aligned} & \text { Full text review of } 27 \text { potentially } \\
& \text { relevant studies }\end{aligned}$
\begin{tabular}{|l|}
\hline 6 included in synthesis: \\
1. X-ray: \\
2. pH testing: \\
3. Ability to obtain aspirate: 3
\end{tabular}

18 excluded:

4. Patients all had artificial airway insitu (4 studies)

5. Study not reported in enough detail to determine balance of artificial airway/not (2 studies)

6. Lack of raw data and inconsistency of results (2 studies)

7. No chest $\mathrm{x}$-ray comparison (1 study)

8. Review or audit articles, not primary research data (9 studies) 
Main file

\section{Figure 2}

A patient who is currently in hospital for surgery who is otherwise fit and well.

They have a nasogastric tube inserted and the position is checked according to the current clinical guidelines.

No complications arise and no treatment is required as a result of the nasogastric tube

A patient who is currently in hospital for surgery who is otherwise fit and well.

They have a nasogastric tube inserted and the position is checked according to the current clinical guidelines.

Some complications arise as a result of the nasogastric tube insertion. The patient experiences some harm from this but it is considered a low amount. No additional treatment is required. They are fully mobile and in some minor pain from the nasogastric tube.

Discharge home will not be delayed.

A patient who is currently in hospital for surgery who is otherwise fit and well.

They have a nasogastric tube inserted and the position is checked according to the current clinical guidelines.

Some major complications arise as a result of the nasogastric tube insertion. The patient experiences harm from this and it is considered a moderate amount. Additional treatment is required but they are cared for in the same ward. Their condition deteriorates but is treated successfully.

Their mobility is limited as a result of these events and they require help to wash, dress and go to the toilet.

Discharge home will be delayed, but not significantly.

A patient who is currently in hospital for surgery who is otherwise fit and well.

They have a nasogastric tube inserted and the position is checked according to the current clinical guidelines.

Some significant complications arise as a result of the nasogastric tube insertion. The patient experiences harm from this and it is considered a severe amount. Additional treatment is required and they require care in the Intensive Care Unit. Their condition deteriorates and they require surgery as a result. Ultimately they are treated successfully.

Their mobility is limited as a result of these events and they require help for all activities.

Discharge home will be significantly delayed.

Figure 2: Extract of vignettes used to rate health states 
CUA OF NG TUBE CHECKING

Main file

Figure 3

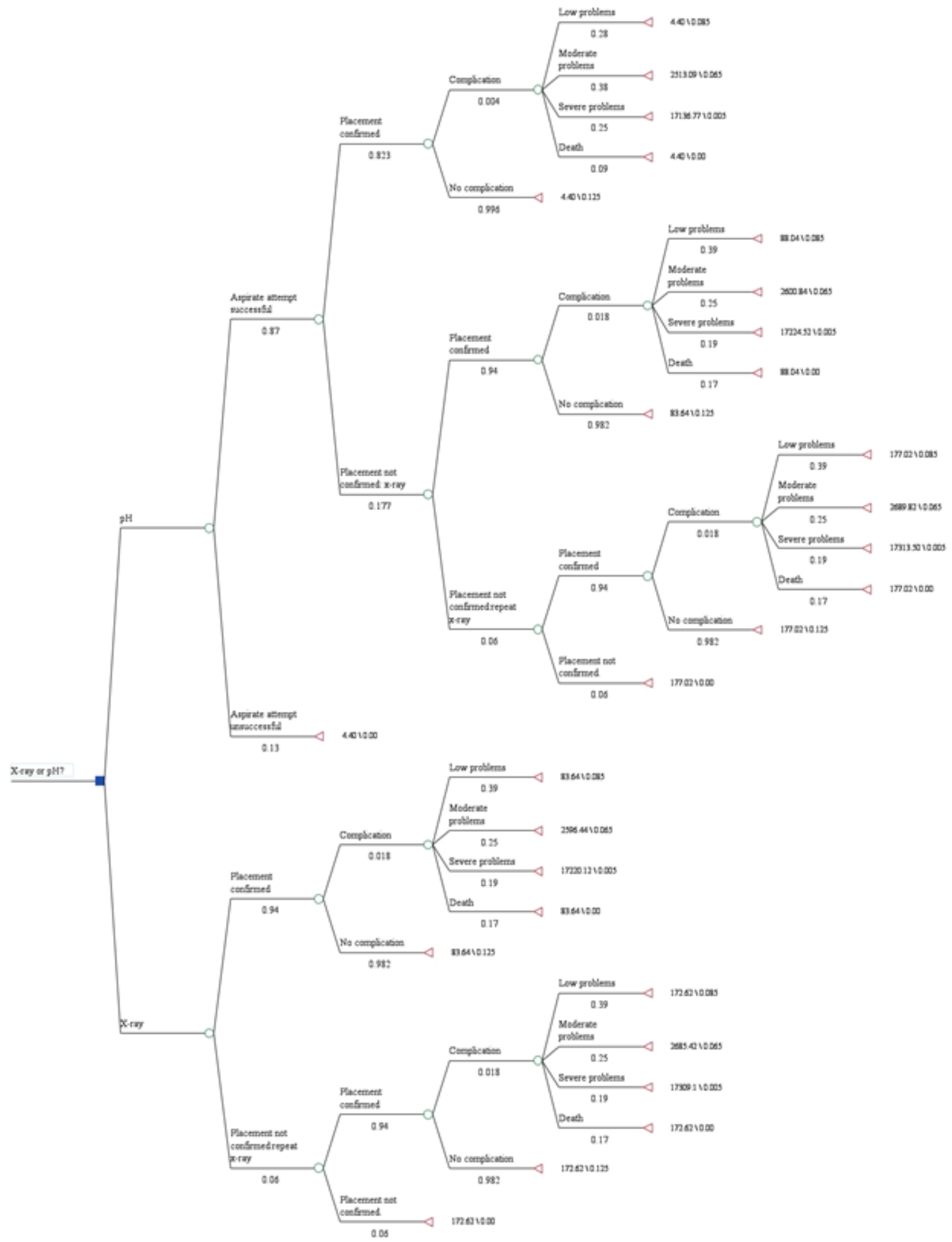

Figure 3: Final decision tree 
Main file

Table 1

\begin{tabular}{|l|l|}
\hline \multicolumn{2}{|c|}{ Criteria for considering studies } \\
\hline Types of studies & - Observational (chest x-ray) \\
& - Diagnostic test accuracy (pH testing) \\
& - Prospective or retrospective \\
& - Examining NGT placement confirmation; x-ray and/or pH testing \\
\hline Types of participants & - Adult patients; defined through admission to an adult care area \\
& \\
& - and/or not defined as paediatric by trialists \\
& - Receiving general care; no artificial airway insitu \\
\hline Types of interventions & - Short term NGT placement for any reason; defined as up to 6 weeks \\
& \\
\hline
\end{tabular}

Table 1: criteria for considering studies for use in synthesis based estimates of effectiveness of both $\mathrm{pH}$ testing and chest $\mathrm{x}$-ray

Table 2

\begin{tabular}{|l|c|c|c|c|c|c}
\hline \multicolumn{7}{|c}{ Summary of effectiveness measure } \\
\hline Chest $x$-ray & $\begin{array}{c}\text { Number of } \\
\text { tubes passed }\end{array}$ & $\begin{array}{c}\text { Number of } \\
\text { complications }\end{array}$ & Low Harm & $\begin{array}{c}\text { Moderate } \\
\text { Harm }\end{array}$ & Severe Harm & Death \\
\hline Source & 340 & 26 & 15 & 7 & 3 & 1 \\
\hline $\begin{array}{l}\text { Gharemani and } \\
\text { Gould (1986) }\end{array}$ & $2273^{*}$ & $23^{*}$ & $3^{*}$ & $5^{*}$ & $7^{*}$ & $8^{*}$ \\
\hline $\begin{array}{l}\text { Sorokin and } \\
\text { Gottlieb (2006) }\end{array}$ & $649^{*}$ & $10^{*}$ & $5 *$ & $3 *$ & $1^{*}$ & $1 *$ \\
\hline $\begin{array}{l}\text { de Aguilar- } \\
\text { Nascimento and } \\
\text { Kudsk (2007) }\end{array}$ & 3262 & 59 & 23 & 15 & 11 & 10 \\
\hline Totals & & 0.018 & 0.39 & 0.25 & 0.19 & 0.17 \\
\hline $\begin{array}{l}\text { Probability } \\
\text { weights }\end{array}$ & & 0.39 & & 19 \\
\hline
\end{tabular}

*indicates limited data set used from study to include only those patients without an artificial airway

Table 2: Summary of effectiveness measures; chest x-ray

Table 3

\begin{tabular}{|l|c|c}
\hline \multicolumn{3}{c}{ Probability of obtaining aspirate for $\mathrm{pH}$ testing } \\
\hline Source & Number of attempts & Aspirate obtained \\
\hline Kearns and Donna (2001) & 380 & 365 \\
\hline Metheny et al (1999) & 511 & $\mathbf{2 6 0}$ \\
\hline $\begin{array}{l}\text { Neumann, Meyer and Dutton } \\
\text { (1995) }\end{array}$ & 33 & 167 \\
\hline Metheny et al (1989) & 181 & 35 \\
\hline Welch et al (1994) & 106 & $\mathbf{1 0 5 5}$ \\
\hline Totals & $\mathbf{1 2 1 1}$ & $\mathbf{0 . 8 7}$ \\
\hline Probability of obtaining aspirate & & \\
\hline
\end{tabular}

Table 3: Probability of obtaining aspirate for $\mathrm{pH}$ testing 
Main file

Table 4

\begin{tabular}{|c|c|c|}
\hline Resource & Amount & Source \\
\hline \multicolumn{3}{|l|}{ NGT placement and confirmation } \\
\hline Nursing time to pass NGT & 12 minutes & Patrick et al (1995) \\
\hline $\begin{array}{l}\text { Nursing time for placement } \\
\text { confirmation }-\mathrm{pH} \text { testing }\end{array}$ & 2 minutes & \multirow[t]{2}{*}{ Kearns and Donna (2001) } \\
\hline $\begin{array}{l}\text { Medical staff time for placement } \\
\text { confirmation - chest x-ray }\end{array}$ & 51 minutes & \\
\hline \multicolumn{3}{|l|}{ Complications - low } \\
\hline \multicolumn{3}{|l|}{ No additional resource required } \\
\hline \multicolumn{3}{|l|}{ Complications - moderate } \\
\hline $\begin{array}{l}\text { Additional nursing time (including } \\
\text { care for increased acuity of } \\
\text { patient and repeated checking } \\
\text { procedures) }\end{array}$ & 24 hours & \multirow{3}{*}{ Dickson and Mann (2011) } \\
\hline $\begin{array}{l}\text { Additional medical staff time } \\
\text { (including chest drain insertion } \\
\text { and care for increased acuity of } \\
\text { patient) }\end{array}$ & 12 hours & \\
\hline Extended stay - ward bed & 36 hours & \\
\hline \multicolumn{3}{|l|}{ Complications - severe } \\
\hline $\begin{array}{l}\text { Additional nursing time - ward } \\
\text { based (including care for } \\
\text { increased acuity of patient, } \\
\text { repeated checking procedures } \\
\text { and transfer to ITU) }\end{array}$ & 24 hours & \multirow{4}{*}{ Lo et al (2008) } \\
\hline $\begin{array}{l}\text { Additional medical staff time - } \\
\text { ward based (including chest drain } \\
\text { insertion, care for increased } \\
\text { acuity of patient and transfer to } \\
\text { ITU) }\end{array}$ & 12 hours & \\
\hline Extended stay - ward bed & 3 days & \\
\hline Extended stay - ITU bed & 6 days & \\
\hline Costs & Amount & Source and details \\
\hline \multicolumn{3}{|l|}{ NGT placement and confirmation } \\
\hline Nursing time to pass NGT & $£ 3.52$ & \multirow{2}{*}{$\begin{array}{l}\text { Agenda for Change pay scale } \\
\text { Band } 5 \text { (midpoint) 2012/13 pay } \\
\text { rates }\end{array}$} \\
\hline $\begin{array}{l}\text { Nursing time for placement } \\
\text { confirmation }-\mathrm{pH} \text { testing }\end{array}$ & $£ 0.59$ & \\
\hline $\begin{array}{l}\text { Medical staff time for placement } \\
\text { confirmation - chest x-ray }\end{array}$ & $£ 23.81$ & $\begin{array}{l}\text { Department of Health basic pay } \\
\text { grade } 3 \text { (midpoint) for SHO } \\
\text { Service of Hospital and Public } \\
\text { Health Medical and Dental Staff } \\
\text { and Community Doctors 2012/13 } \\
\text { at x } 1 \text { hourly rate }\end{array}$ \\
\hline First chest x-ray & $f 56.13$ & $\begin{array}{l}\text { ISD Scotland (2012) } \\
\text { Radiology services tariff }\end{array}$ \\
\hline $\begin{array}{l}\text { pH test consumables (including } \\
\text { cost of syringe for aspiration and } \\
\text { pH paper) }\end{array}$ & f0.29 & $\begin{array}{l}\text { BD } 10 \mathrm{ml} \text { luer lock syringe } \times 1 \\
\mathrm{pH} \text { paper } \times 1 \text { test from } 160 \text { pack }\end{array}$ \\
\hline \multicolumn{3}{|l|}{ Complications - low } \\
\hline \multicolumn{3}{|l|}{ No additional costs required } \\
\hline \multicolumn{3}{|l|}{ Complications - moderate } \\
\hline Additional nursing time & $£ 421.92$ & $\begin{array}{l}\text { Agenda for Change pay scale } \\
\text { Band } 5 \text { (midpoint) 2012/13 pay } \\
\text { rates }\end{array}$ \\
\hline
\end{tabular}


Main file

\begin{tabular}{|c|c|c|}
\hline Additional medical staff time & f285.72 & $\begin{array}{l}\text { Department of Health basic pay } \\
\text { grade } 3 \text { (midpoint) for SHO } \\
\text { Service of Hospital and Public } \\
\text { Health Medical and Dental Staff } \\
\text { and Community Doctors } 2012 / 13 \\
\text { at x } 12 \text { hourly rate }\end{array}$ \\
\hline Extended stay - ward bed & $£ 382.50$ & $\begin{array}{l}\text { Department of Health (2012) } \\
\text { Reference costs for excess bed } \\
\text { stay } x 1.5 \text { days }\end{array}$ \\
\hline Chest drain insertion & $£ 1306$ & $\begin{array}{l}\text { ISD Scotland ( } 2012 \mathrm{~b}) \\
\text { National Tariff input for non- } \\
\text { elective minor thoracic } \\
\text { procedures }\end{array}$ \\
\hline $\begin{array}{l}\text { Repeat chest } x \text {-ray } \times 2 \text { (pre and } \\
\text { post chest drain insertion) }\end{array}$ & f112.26 & $\begin{array}{l}\text { ISD Scotland (2012b) } \\
\text { Radiology services tariff } \times 2\end{array}$ \\
\hline Repeat $\mathrm{pH}$ test consumables & $£ 0.29$ & As above \\
\hline \multicolumn{3}{|l|}{ Complications - severe } \\
\hline $\begin{array}{l}\text { Additional nursing time - ward } \\
\text { based }\end{array}$ & $£ 421.92$ & \multirow{2}{*}{ As above } \\
\hline $\begin{array}{l}\text { Additional medical staff time - } \\
\text { ward based }\end{array}$ & £285.72 & \\
\hline Extended stay - ward bed & $£ 765$ & $\begin{array}{l}\text { Department of Health (2012) } \\
\text { Reference costs for excess bed } \\
\text { stay x } 3 \text { days }\end{array}$ \\
\hline Extended stay - ITU bed & f12384 & $\begin{array}{l}\text { ISD Scotland ( } 2012 \mathrm{~b}) \\
\text { National Tariff input for critical } \\
\text { care service ITU per day x } 6\end{array}$ \\
\hline $\begin{array}{l}\text { Repeat chest } x \text {-ray } x 3 \text { (pre and } \\
\text { post chest drain insertion, post } \\
\text { ETT insertion) }\end{array}$ & $£ 168.39$ & $\begin{array}{l}\text { ISD Scotland (2012b) } \\
\text { Radiology services tariff x } 3\end{array}$ \\
\hline Chest drain insertion & $£ 1306$ & $\begin{array}{l}\text { ISD Scotland ( } 2012 \mathrm{~b}) \\
\text { National Tariff input for non- } \\
\text { elective minor thoracic } \\
\text { procedures }\end{array}$ \\
\hline Repeat $\mathrm{pH}$ test consumables & $£ 0.29$ & As above \\
\hline \multicolumn{3}{|l|}{ Summary costs } \\
\hline \multicolumn{3}{|l|}{$p H$} \\
\hline \multicolumn{2}{|l|}{ No complications } & 4.40 \\
\hline \multicolumn{2}{|l|}{ Low complications } & 4.40 \\
\hline \multicolumn{2}{|l|}{ Moderate complications } & 2513.09 \\
\hline \multicolumn{2}{|l|}{ Severe complications } & 17136.77 \\
\hline \multicolumn{3}{|l|}{$X-R a y$} \\
\hline \multicolumn{2}{|l|}{ No complications } & 83.64 \\
\hline \multicolumn{2}{|l|}{ Low complications } & 83.64 \\
\hline \multicolumn{2}{|l|}{ Moderate complications } & 2596.44 \\
\hline \multicolumn{2}{|l|}{ Severe complications } & 17220.12 \\
\hline \multicolumn{3}{|l|}{ Cost per positive repeat $x$-ray } \\
\hline \multicolumn{2}{|l|}{ 2nd x-ray } & f88.98 \\
\hline \multicolumn{2}{|l|}{ 3rd x-ray } & f89.51 \\
\hline \multicolumn{2}{|l|}{ 4th x-ray } & f88.98 \\
\hline
\end{tabular}

Table 4: Cost and resource inputs including summary estimates of costs of placement confirmation, complications and repeated chest $\mathrm{x}$-rays 
CUA OF NG TUBE CHECKING

Main file

Table 5

\begin{tabular}{|c|c|c|c|c|}
\hline & $\begin{array}{l}\text { Health state } 1 \\
\text { No complications }\end{array}$ & $\begin{array}{l}\text { Health state } 2 \\
\text { Low complications }\end{array}$ & $\begin{array}{l}\text { Health state } 3 \\
\text { Moderate } \\
\text { complications }\end{array}$ & $\begin{array}{l}\text { Health state } 4 \\
\text { Severe } \\
\text { complications }\end{array}$ \\
\hline \multicolumn{5}{|c|}{ Summary EQ-5D index values } \\
\hline Mean & 0.897 & 0.672 & 0.491 & 0.109 \\
\hline$S E$ & 0.042 & 0.018 & 0.036 & 0.025 \\
\hline Median & 1.00 & 0.678 & 0.523 & 0.036 \\
\hline $25^{t h}$ & 0.796 & 0.592 & 0.378 & 0.036 \\
\hline $75^{\text {th }}$ & 1.00 & 0.7365 & 0.592 & 0.167 \\
\hline \multicolumn{5}{|c|}{ Summary - EQ5D VAS values } \\
\hline Mean & 0.910 & 0.759 & 0.599 & 0.440 \\
\hline SE & 0.009 & 0.017 & 0.024 & 0.022 \\
\hline Median & 0.9 & 0.75 & 0.63 & 0.4 \\
\hline $25^{\text {th }}$ & 0.9 & 0.7 & 0.5 & 0.35 \\
\hline $75^{\text {th }}$ & 0.95 & 0.85 & 0.7 & 0.5 \\
\hline \multicolumn{5}{|c|}{$\begin{array}{l}\text { Health state index conversion to } Q A L Y \text { value } \\
Q A L Y=\text { utility value of health state } x \text { length of time in health state }\end{array}$} \\
\hline Mean & 0.112 & 0.084 & 0.061 & 0.014 \\
\hline Median & 0.125 & 0.085 & 0.065 & 0.005 \\
\hline $25^{t h}$ & 0.01 & 0.074 & 0.047 & 0.005 \\
\hline $75^{\text {th }}$ & 0.125 & 0.092 & 0.074 & 0.021 \\
\hline
\end{tabular}


CUA OF NG TUBE CHECKING

Main file

Table 6

\begin{tabular}{|c|c|c|c|c|c|c|}
\hline & $\begin{array}{c}\text { Incremental } \\
\text { cost (f) } \\
\mathrm{pH} \\
\end{array}$ & $\begin{array}{c}\text { QALY gained } \\
\mathrm{pH}\end{array}$ & $\begin{array}{c}\text { ICER (cost } \\
\text { per QALY } \\
\text { gained, } \mathrm{f} \text { ) pH } \\
\end{array}$ & $\begin{array}{c}\text { Incremental } \\
\text { cost ( } f) \\
\text { X-ray } \\
\end{array}$ & $\begin{array}{c}\text { QALY gained } \\
X \text {-ray }\end{array}$ & $\begin{array}{l}\text { ICER (cost per } \\
\text { QALY gained, } \\
\text { £) X-ray }\end{array}$ \\
\hline Base case & 43.20 & 0.11 & 392.73 & 158.64 & 0.12 & 1322.00 \\
\hline \multicolumn{7}{|l|}{ Effectiveness } \\
\hline \multicolumn{7}{|c|}{ Aspiration success rate } \\
\hline $\begin{array}{l}0.33 \text { success } \\
\text { (Welch et al 1994) }\end{array}$ & 19.12 & 0.04 & 478.00 & 158.64 & 0.12 & 1322.00 \\
\hline $\begin{array}{l}0.93 \text { success } \\
\text { (Metheny et al 1989) }\end{array}$ & 45.88 & 0.12 & 382.33 & 158.64 & 0.12 & 1322.00 \\
\hline \multicolumn{7}{|c|}{ pH confirmation rate } \\
\hline $\begin{array}{l}0.803 \text { (lower } \mathrm{Cl} \text { of } \\
\text { meta-analysis) }\end{array}$ & 45.53 & 0.11 & 413.91 & 158.64 & 0.12 & 1322.00 \\
\hline $\begin{array}{l}0.843 \text { (upper } \mathrm{Cl} \text { of } \\
\text { meta-analysis) }\end{array}$ & 40.88 & 0.11 & 371.64 & 158.64 & 0.12 & 1322.00 \\
\hline \multicolumn{7}{|c|}{ Chest $x$-ray complication rate } \\
\hline $\begin{array}{l}0.076 \text { (Gharemani } \\
\text { and Gould 1986) }\end{array}$ & 77.80 & 0.11 & 707.27 & 383.11 & 0.12 & 3192.58 \\
\hline $\begin{array}{l}0.010 \text { (Sorokin and } \\
\text { Gottlieb 2006) }\end{array}$ & 38.43 & 0.11 & 349.36 & 127.68 & 0.12 & 1064.00 \\
\hline \multicolumn{7}{|l|}{ Utility } \\
\hline $25^{\text {th }}$ percentile & 43.20 & 0.11 & 392.73 & 158.64 & 0.12 & 1322.00 \\
\hline $75^{\text {th }}$ percentile & 43.20 & 0.12 & 360.00 & 158.64 & 0.12 & 1322.00 \\
\hline Mean utility & 43.20 & 0.11 & 392.73 & 158.64 & 0.12 & 1322.00 \\
\hline $\begin{array}{l}\text { VAS utility } \\
\text { (median) }\end{array}$ & 43.20 & 0.10 & 432.00 & 158.64 & 0.11 & 1442.18 \\
\hline \multicolumn{7}{|l|}{ Cost } \\
\hline $\begin{array}{l}\text { Cost of death = } \\
\text { severe } \\
\text { complications }\end{array}$ & 55.66 & 0.11 & 506.00 & 210.89 & 0.12 & 1757.42 \\
\hline
\end{tabular}

Table 5: Base case cost utility results and sensitivity analyses 